\title{
Intervention in Takayasu Aortitis: When, Where and How?
}

\author{
Andrew Porter ${ }^{1, *}$ and Justin C. Mason 1,2 \\ 1 Rheumatology Department, Imperial College Healthcare NHS Trust, Hammersmith Hospital, \\ London W12 OHS, UK; justin.mason@imperial.ac.uk \\ 2 National Heart and Lung Institute, Imperial College London, London W12 ONN, UK \\ * Correspondence: andrew.porter8@nhs.net
}

Received: 13 July 2020; Accepted: 31 July 2020; Published: 5 August 2020

\begin{abstract}
Takayasu arteritis is a large vessel vasculitis which commonly affects the aorta and its major branches. Active arterial inflammation is characterised by the presence of $\mathrm{T}$ and $\mathrm{B}$ lymphocytes, natural killer cells, macrophages and occasional multinucleate giant cells. Uncontrolled vascular inflammation can progress to cause arterial stenosis, occlusion or aneurysmal dilatation. Medical treatment involves combination immunosuppression and more recently biologic therapies targeting TNF- $\alpha$ and IL-6. Due to the typical delays in diagnosis and accumulation of arterial injury, open and endovascular surgical intervention are important and potentially life-saving treatment options for Takayasu arteritis. Common indications for surgery include aortic coarctation and ascending aortic dilatation \pm aortic valve regurgitation, renal artery stenosis, ischaemic heart disease, supra-aortic disease, mesenteric ischaemia, severe limb-threatening claudication and aneurysm repair. Surgical outcomes are markedly improved in patients with clinically inactive disease and those who receive adequate periprocedural immunosuppression. Decisions regarding surgical approaches are best made as part of a multi-disciplinary team.
\end{abstract}

Keywords: Takayasu arteritis; aortitis; endovascular intervention; open surgery

\section{Introduction}

Takayasu arteritis is one of the large vessel vasculitides, classified alongside giant cell arteritis [1]. Although the disease most commonly affects young adult females, it may present during childhood, often in a severe form [2], and is seen in both sexes and in all races. This systemic inflammatory disease begins in the arterial adventitia and vasa vasora. Arterial inflammation and injury is present most commonly in the aorta and its major branches [3,4], with pulmonary artery lesions seen in up to $50 \%$ of patients [5]. Intense, focal areas of inflammation involve all layers of the arterial wall. Accompanied by oedema, inflammation results in concentric arterial wall thickening and this may progress to arterial stenosis and occlusion [6]. While aneurysmal dilatation is less commonly seen, it more often requires surgical intervention [7].

Non-invasive imaging now plays a critical role in all aspects of Takayasu arteritis management. The modalities most commonly used include high resolution Doppler ultrasound, magnetic resonance (MRA) and computed tomography angiography (CTA) [8,9]. Likewise, positron emission tomography has proved particularly valuable for the diagnosis of Takayasu arteritis, with $2-\left[{ }^{18} \mathrm{~F}\right]-$ fluoro2-deoxy-D-glucose PET with CT $\left({ }^{18} \mathrm{~F}\right.$-FDG-PET $\left.{ }^{-} \mathrm{CT}\right)$ able to identify areas of intense metabolic activity within the arterial wall that is indicative of inflammation (Figure 1) $[10,11]$. The detailed anatomic assessment associated with US, MRA and CTA all play important roles in the diagnosis of Takayasu arteritis and represent a central component of follow-up. In particular, the lack of radiation and wide coverage of the aorta and its branches provided by MRA offers a safe and effective means to conduct 
long-term monitoring [12]. Imaging data confirm that the aorta is involved in more than $95 \%$ of patients with Takayasu arteritis. Specific findings may include one or more of arterial wall inflammation and thickening, stenosis, occlusion and less commonly aneurysm formation [13]. All regions of the aorta may be involved (Figure 2) and while disease may be confined to the aorta, additional involvement of branch arteries is typical (Figure 3) [14].

Although in the majority of cases, Takayasu arteritis can be treated medically, the typical delay in diagnosis leads to accumulation of arterial injury [15]. Outcomes are now improving following more widespread use of early combination immunosuppression and wider availability of biologic therapies targeting TNF- $\alpha$ and IL-6 for refractory disease [4]. When indicated, open and endovascular surgical intervention remain important and potentially life-saving treatment options for Takayasu arteritis.

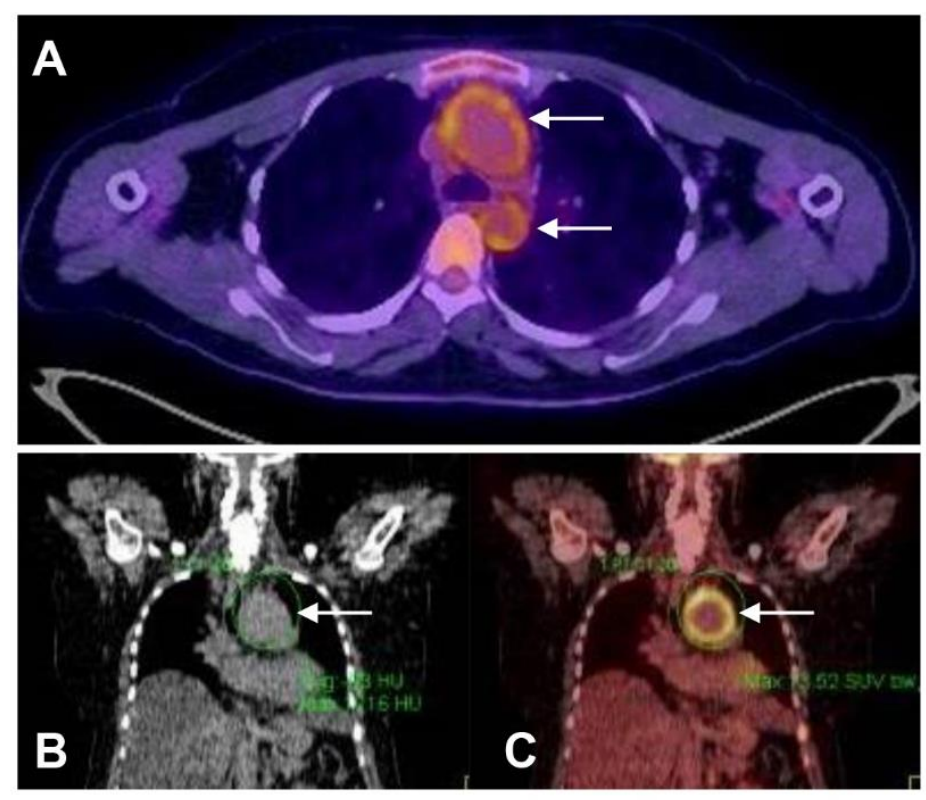

Figure 1. FDG Positron emission tomography. (A) ${ }^{18}$ FDG-PET-CT scan demonstrating tracer uptake in the ascending and descending aorta (arrows) consistent with active Takayasu arteritis in a young female. (B) CT scan of a 45 year-old female reveals aneurysmal dilatation of the aortic arch (arrows). (C) The matched ${ }^{18}$ FDG-PET-CT scan reveals intense FDG avidity localised to the wall of the aneurysm (maximum standardised uptake value 13.5).
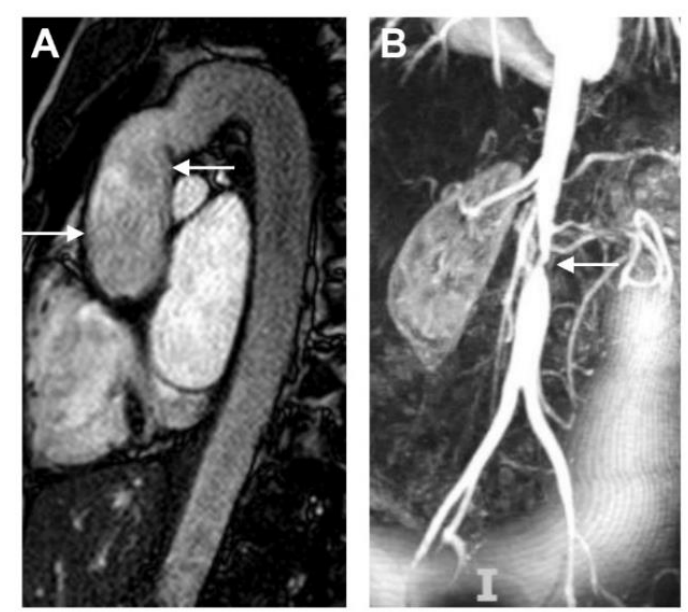

Figure 2. Cont. 

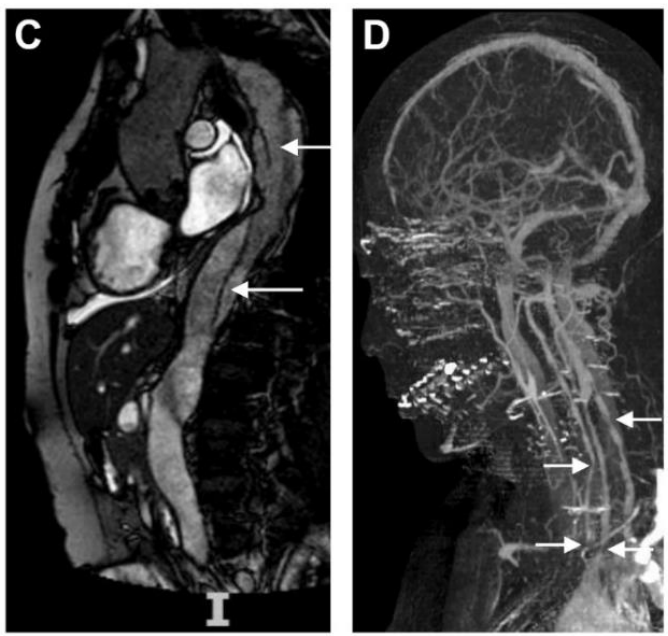

Figure 2. Aortic and supra-aortic disease. (A) Post-operative MR angiography showing successful aortic valve and root replacement in a young female with Takayasu arteritis who presented with severe aortic regurgitation (arrows). (B) MR angiogram (MRA) in a 26 year-old female with Takayasu arteritis demonstrating significant stenosis of the abdominal aorta in the region of the renal arteries sufficient to restrict blood flow to the lower limbs and induce symptoms of intermittent claudication on exertion. (C) Type B aortic dissection in Takayasu arteritis (arrows). The lesion extends from proximal descending thoracic aorta to the proximal abdominal aorta just beyond the renal arteries. There is relative narrowing of the true lumen compared with the false lumen. (D) Severe supra-aortic disease in a 37 year-old female with Takayasu arteritis. There is evidence for multiple stenoses in the great vessels arising from the aortic arch and in the vertebral arteries (arrows).

This review will focus on surgical approaches in Takayasu arteritis and how they may be optimally applied. Open surgery is well established and outcome data are good. Endovascular intervention involving primary angioplasty, with or without stenting, is most commonly used in the treatment of aortic branch arteries including the visceral arteries. Increasingly, the role of aortic stent grafts and individually designed endovascular stents is being explored. However, experience is limited and long-term outcome data have yet to be published.
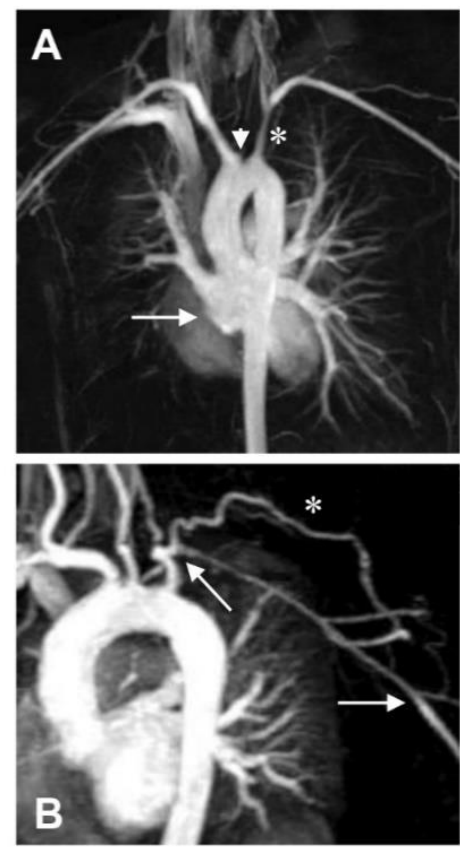

Figure 3. Cont. 


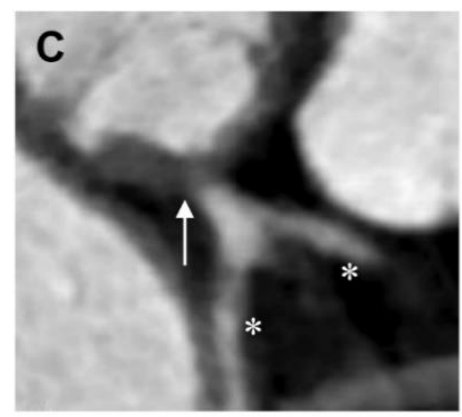

Figure 3. Involvement of branch arteries in Takayasu arteritis. (A) MR angiogram demonstrating severe stenosis of the right middle and lower lobe pulmonary arteries in a 29 year-old female with Takayasu arteritis (arrow). The left common carotid artery is also occluded (arrowhead) and there is stenosis of the left subclavian artery (star). (B) MRA demonstrating a long subclavian artery stenosis (arrows), with a well-established collateral circulation (star) and good distal run-off. (C) Coronary CT angiography revealing aortitis extending to involve the left main stem which is stenosed (arrow) and was treated by coronary artery bypass grafting (stars).

\section{Pathogenesis}

The immune response in Takayasu arteritis is likely antigen driven and initiated in the adventitia where vascular dendritic cells, located close to the external elastic lamina, act as arterial wall gatekeepers. Initiating factors have yet to be identified and are thought to act via differentially located Toll-like receptors that may influence lesion location and pattern in large vessel vasculitis [16]. Emerging data suggest that the host genetic background also plays an important role in disease susceptibility [17]. Immunohistochemical analysis of arterial specimens reveals focal inflammatory infiltrates which span the adventitia to the intima. The vasa vasora proliferate and allow mononuclear cell infiltration into the arterial wall. Active arterial inflammation is characterised by the presence of $\mathrm{T}$ and $\mathrm{B}$ lymphocytes, natural killer cells, macrophages and occasional multinucleate giant cells. Lymphoid follicles may form in the adventitial layer [18]. Remodeling occurs as a consequence of arterial wall thickening and stromal cell proliferation resulting in arterial lumen stenosis/occlusion which is eventually replaced by fibrosis. On occasion local arterial wall injury and disruption of the elastic laminae leads to progressive degeneration and aneurysm formation [4].

\section{Patterns of Aortic Disease}

Review of imaging and angiographic data have demonstrated that both the distribution and degree of arterial involvement in patients with Takayasu arteritis varies. Different classification systems have been suggested based on patterns of disease to define patient subgroups. One of the original classification schemes is the Numano system, which is a modification of the Nasu classification. This describes five disease patterns ranging from involvement of the ascending aorta or one of the supra-aortic vessels alone, up to pan-aortic disease (Table 1) $[19,20]$. There are some limitations including suboptimal differentiation of patients, with the majority classified as Type $V$ disease [21,22]. In addition to this, the Numano classification has not been shown to demonstrate clinical prognostic value.

More recently computer-based methods, using cluster analysis, have been able to identify patterns of angiographic disease in Takayasu arteritis. Based on the assessment of vascular lesions in 13 territories, patients were classified into three clusters; abdominal predominant, aortic arch predominant or focal disease (Table 2) [23]. Unlike the Numano classification, these cluster subgroups appear to be more clinically relevant, with significant associations between cluster classification and clinical features of disease including stroke, hypertension and likelihood of obtaining clinical remission identified [23].

Differing patterns of vascular injury are seen depending on the type and the location of the affected artery. Disease affecting the supra-aortic vessels most commonly leads to stenosis of the 
common carotid and subclavian arteries [24]. This can compromise cerebral blood supply, resulting in symptoms of cerebral ischaemia including visual impairment, dysphasia, transient hemiparesis, loss of consciousness and stroke [25]. In contrast, ascending aortitis may be associated with ostial coronary artery stenoses and with dilatation or aneurysm formation in the ascending aorta and aortic arch, which is often accompanied by aortic valve regurgitation [26]. Disease of the thoracic aorta may also result in aneurysmal dilation and increase the risk of aortic dissection. Distal aortic stenotic disease is typically accompanied by lower limb claudication. Visceral arterial involvement can affect the renal, mesenteric and coeliac arteries. Stenotic lesions affecting these arteries are typically ostial in nature, whereas those in the subclavian/axillary arteries are often long and irregular (Figure 3B) [26].

Table 1. Numano classification for arterial involvement in Takayasu arteritis.

\begin{tabular}{|c|c|}
\hline Type I & involves primarily the branches from the aortic arch. \\
\hline Type IIa & involves the ascending aorta, aortic arch and its branches. \\
\hline Type IIb & involves the ascending aorta, aortic arch with its branches and thoracic descending aorta. \\
\hline Type III & involves the thoracic descending aorta, abdominal aorta and/or renal arteries. \\
\hline Type IV & affects only the abdominal aorta and/or renal arteries. \\
\hline Type V & affects the combined features of both type IIb and IV. \\
\hline
\end{tabular}

Table 2. Cluster analysis to identify patterns of angiographic disease in Takayasu arteritis.

\begin{tabular}{ll}
\hline $\begin{array}{l}\text { Cluster 1 (Abdominal } \\
\text { predominant) }\end{array}$ & $\begin{array}{l}\text { arterial involvement of abdominal arteries including the abdominal aorta, } \\
\text { mesenteric arteries and renal arteries. Patients were more likely to have renal } \\
\text { hypertension and mesenteric ischaemia. }\end{array}$ \\
\hline $\begin{array}{l}\text { Cluster 2 (Aortic arch } \\
\text { predominant) }\end{array}$ & $\begin{array}{l}\text { arterial involvement in branches of the aortic arch including the carotid and } \\
\text { subclavian arteries. Patients were more likely to have a history of stroke, } \\
\text { carotidynia and light headedness and were less likely to achieve clinical remission. }\end{array}$ \\
\hline Cluster 3 (Focal disease) & $\begin{array}{l}\text { asymmetric arterial involvement with focal disease. Patients were less likely to } \\
\text { have occlusive and damaging disease. }\end{array}$ \\
\hline
\end{tabular}

\section{Medical Treatment of Takayasu Arteritis}

The primary aim of medical treatment in Takayasu arteritis is to suppress vessel inflammation, induce and maintain disease remission to prevent the development of vascular complications. Corticosteroids have been the mainstay of therapy and are effective in controlling Takayasu arteritisassociated inflammation. Long-term corticosteroid use leads to significant side effects and there is a high chance of relapse when the dose is tapered or stopped [27]. Small open-label studies have reported efficacy of methotrexate, azathioprine, mycophenolate mofetil and leflunomide as disease-modifying anti-rheumatic drugs (DMARDs) in Takayasu arteritis [28-31]. Cyclophosphamide is reserved for those with life-threatening disease including myocarditis and symptomatic cerebral ischaemia [32].

Disease refractory to conventional immunosuppressive therapy is seen $15-20 \%$ of patients. In these cases, biologic therapy with either anti-IL-6 receptor monoclonal antibodies or tumour necrosis factor- $\alpha$ antagonists can be considered [4]. Availability of these drugs varies around the world. In the UK, funding for tocilizumab (anti-IL-6 receptor monoclonal antibody) can be prescribed for those who have disease refractory to corticosteroids and at least two conventional synthetic DMARDs [33].

\section{Indications for Surgery}

Although surgical interventions play an important role in the management of Takayasu arteritis, they should only be considered following failure of medical therapy to control arterial injury. A recent series of patients being considered for revascularisation surgery for severe supra-aortic Takayasu arteritis, complicated by cerebral ischaemia, were switched to biologic therapy. This led to significant 
improvement in symptoms and obviated the need for surgical intervention [25]. Thus, appropriate patient selection is key when considering surgery.

This is exemplified by a retrospective study which divided 106 Japanese patients who had undergone surgery for Takayasu arteritis into three groups based upon severity criteria [34]. In those with the most severe disease (stage III) with $\geq 2$ major complications including aortic regurgitation, severe hypertension or aneurysm development, the 15 -year survival rate was increased from $43 \%$ to $67.5 \%$ following the addition of surgical intervention [35]. However, those graded as stage II derived no survival benefit, whilst those with stage I who underwent surgery had shortened survival [35].

Across a number of series, the main indications for surgery are: refractory hypertension related to renal artery stenosis, aortic disease including coarctation and ascending aortic dilatation \pm aortic valve regurgitation, ischaemic heart disease, supra-aortic disease with cerebral ischaemia, mesenteric ischaemia, severe limb-threatening claudication and aneurysm repair [26,36,37] (Figures 2 and 3).

Although the predominant indications for revascularisation are agreed worldwide, comparison of patient cohorts showed the proportion of patients undergoing surgery (both open and endovascular interventions) ranged from $11.7 \%$ to $70 \%$ (Table 3 ) $[7,27,34,38,39]$. This may represent different patterns of referral, local expertise and case mix. The commonest lesions treated are arterial stenoses/occlusions, followed by surgery for aortic regurgitation and aneurysms $[7,38,40]$.

Table 3. The proportion of patients undergoing surgery from different cohorts

\begin{tabular}{ccc}
\hline Study & Country & Rates of Surgery \\
\hline Fields et al. [38] & USA & $17 \%$ \\
Maksimowicz-McKinnon et al. [27] & USA & $70 \%$ \\
Perera et al. [7] & UK & $38 \%$ \\
Ishikawa et al. [34] & Japan & $11.7 \%$ \\
Ohigashi et al. [39] & Japan & $22.6 \%$ \\
\hline
\end{tabular}

\section{Pre-Operative Assessment of Disease Activity}

In patients with Takayasu arteritis in long-term remission and who have been withdrawn from immunosuppression, surgical outcomes are excellent with revision rates reported as zero at 10 years [38]. However, this situation is relatively rare and recurrence rates rise significantly in those requiring surgical intervention when in remission on immune suppression and especially in those with active disease [38]. Thus it is important, whenever possible, to achieve disease remission with medical therapy prior to surgery [26]. Patients who have clinically inactive disease and who receive adequate periprocedural immunosuppression have significantly improved outcomes $[7,38,40]$.

Assessment of disease activity in large vessel vasculitis is an imperfect science. If the situation allows, surgery should be delayed until the Indian Takayasu activity score (ITAS-A) and physician's global assessment indicate clinically inactive disease [41]. The normalisation of indices including erythrocyte sedimentation rate, C-reactive protein, haemoglobin, albumin and platelet count is indicative of suppressed inflammation in all cases. Prior to aortic surgery in particular, ${ }^{18} \mathrm{~F}-\mathrm{FDG}$-PET-CT may help to exclude persistent arterial wall inflammation (Figure 1). While a negative scan does not completely rule out active disease [42], a positive scan is an indicator that surgery should be delayed 3-6 months while immunosuppression is enhanced, providing the clinical situation allows.

For those receiving immunosuppression including biologic therapies at the time of surgery, we recommend that this is continued throughout the surgical period. We also advocate pre- and post-procedure intravenous hydrocortisone (100-200 mg) in all patients. Available data suggest that this approach to medical therapy improves surgical outcomes without significantly increasing the risks of complications including post-operative infection and further prospective studies are now required to confirm this [38]. 


\section{Endovascular versus Open Surgery}

The emergence of sophisticated endovascular approaches to aortic surgery has begun to impact the management of aortitis. However, further research is needed to establish the most effective approaches for surgical intervention. The nature of the lesion under consideration is critical, with aneurysms posing a different challenge to stenoses. Likewise, the approaches taken for the aorta may differ to those more commonly applied to the branch arteries. Stenoses as a complication of arteritis are typically fixed and fibrous in nature. They can be difficult to cross with a guidewire and challenging to adequately inflate with a balloon. Interventional approaches adopted may vary from centre to centre, with some favouring the more durable outcomes associated with open surgery, while others prefer the less invasive endovascular methods [38,43]. Although data are relatively sparse for Takayasu arteritis, both open and endovascular surgical approaches have been employed in all vascular beds [26]. A recent meta-analysis included 770 patients and 1363 lesions. Of these, 389 patients were treated endovascularly and 420 underwent surgical revascularisation [44]. Overall, the incidence of restenosis was lower following open surgery. Morbidity and mortality were equivalent, except for a higher incidence of stroke following open surgery.

The most commonly performed aortic surgery in Takayasu arteritis is aortic valve \pm aortic root replacement. Open surgery is most commonly employed and is associated with excellent long-term outcomes, even in the face of active aortitis, although late aortic dilatation is more commonly seen in this event [45]. In the thoracic and abdominal aorta, aneurysms are most commonly treated with open surgery, although aortic stents and stent grafts now offer a viable alternative for some. Stenotic lesions in the thoracoabdominal aorta remain extremely challenging, particularly those close to or involving visceral arteries. In many, a robust collateral circulation develops which obviates the need for surgical intervention. More distal lesions, especially where limiting lower limb claudication is reported, can be effectively treated with an aorto-bi-iliac/femoral graft $[38,46]$. Angioplasty with stenting has also been applied successfully for the treatment of aortic stenoses [47,48].

Outside the aorta, angioplasty is commonly employed for the treatment of stenoses in branch arteries. Although opinion remains divided on the use of stents, most studies have reported higher restenosis and recurrence rates when stents are deployed when compared to angioplasty alone [43,44,49-52]. Increasingly, stents are reserved for the treatment of procedural complications such as dissection or for recurrent lesions. Guidelines for the use of angioplasty and stenting in this setting do not exist, although outcomes are markedly improved if the arteritis activity is controlled. Typically, anti-platelet agents (aspirin and/or clopidogrel) are recommended for 3 days prior to the procedure with dual therapy for those undergoing insertion of a stent. Heparin is typically prescribed during the procedure. For urgent and more complex procedures, dual platelet therapy is often continued for 3 months with lifelong aspirin in those with a stent. For lower risk procedures in well-controlled disease clopidogrel is recommended for 3 months post-procedure [50].

Stent grafts offer significant potential for the management of the complications of aortitis. However, data concerning their efficacy and longevity remain sparse. They comprise a metal stent with an impervious fabric lining and they expand to mirror the shape of the artery in which they are deployed. Eight patients treated with either stent grafts or bare metal stents were retrospectively reviewed. Initial results were comparable, however the stent grafts remained patent longer, with secondary intervention required less often [50].

Decisions regarding surgical approaches in these settings are best made as part of a multi-disciplinary team, typically involving cardiothoracic and vascular surgeons, interventional radiologists, rheumatologists, cardiologists and renal physicians. Careful informed discussion with the patient is critical to outline the pros and cons and to determine their preferences. The age of the patient and the variability in patency duration between angioplasty \pm stenting and open surgery must be carefully considered. Finally, a second-line strategy must be planned in the event of a short or long-term failure of the primary approach. 


\section{Surgical Approaches}

\subsection{Supra-Aortic Disease and Cerebral Ischemia}

Patients with severe involvement of the supra-aortic arteries may develop symptomatic cerebral ischaemia (Figure 2D). Both open and endovascular surgical approaches have been adopted in those with refractory symptoms despite optimal medical therapy. Aorto-carotid bypass is the most commonly used procedure $[53,54]$. The risk of complications are higher with open surgery, however there is superior long-term patency with restenosis rates approximately $12.5 \%$ [53,55]. The presence of long occluded segments may render endovascular intervention impossible or increase the risk of side-effects and recurrence. Thus, these procedures are reserved for patients with short-focal lesions, or those considered to be very high risk for open surgery [56]. Tight blood pressure control and unilateral, as opposed to bilateral aorto-carotid bypass, reduces the risk of cerebral hyperperfusion \pm haemorrhage [53,54].

\subsection{Subclavian/Axillary Arteries}

Involvement of the subclavian/axillary arteries in Takayasu arteritis is frequently associated with symptoms of upper limb ischemia on exertion. Typically, these stenotic lesions are long, irregular and fibrotic in nature (Figure 3B). In light of this, angioplasty is technically challenging compared to conventional atherosclerotic lesions [57]. Open surgery involving upper limb arteries is often complicated by difficult anastomoses to relatively small distal arteries and the risk of restenosis is high $[36,57]$. In many centres, intervention is avoided and confined only to those with limb-threatening ischemia or to short proximal lesions amenable to angioplasty. Instead, an upper limb exercise programme is encouraged to aid development of a collateral circulation (Figure 3B).

\subsection{Disease of the Aorta}

One of the most common sites for surgical intervention is the aorta and aortic valve [36,40]. Ascending aortitis can result in aortic root dilatation and aortic valve regurgitation. Often aortic valve replacement is accompanied by the replacement of the ascending aorta with a graft (Figure 2A). Outcomes are good and improved by the surgery being carried out in specialist centres $[45,58]$. Patients require lifelong monitoring following aortic valve replacement with regular imaging, as late aneurysmal dilatation of the ascending aorta can occur [7]. MRA is preferred to CTA in order to minimise exposure to ionising radiation.

Aortic aneurysms are a relatively rare but an important consideration and can be identified at sites throughout the aorta [59]. Close monitoring is required and those which are less than $2 \mathrm{~cm}$ with no evidence of progressive enlargement do not need intervention [60]. Both open repair with prosthetic grafts and endovascular approaches with stents to occlude aneurysms can be considered $[7,61]$. ${ }^{18}$ F-FDG-PET-CT can be employed to identify persistent inflammation in the wall of the aneurysm which increases the risk of rupture (Figure 1) [42].

Surgical interventions in aortic coarctation are particularly challenging (Figure 2B) and are usually limited to those with severe lower limb claudication or refractory hypertension [38]. Open aorto-bi-iliac grafts typically resolve the symptoms of limiting claudication; however, improved blood pressure control is only seen in $40-50 \%$ of patients post-operatively [38,46,62]. Endovascular interventions can be successful in carefully selected patients although repeat angioplasty may be required $[43,50,63]$.

Aortic dissection is a rare complication in Takayasu arteritis (Figure 2C). In one retrospective study of 1154 patients, only 10 patients $(0.87 \%)$ with aortic dissection were identified [64]. Stanford type $\mathrm{B}$ was the predominant anatomic classification. Nine patients received conservative treatment with antihypertensives and immunosuppression and one underwent endovascular repair due to extensive dissection [64]. 


\subsection{Coronary Arteries}

The coronary arteries can be affected in Takayasu arteritis by both vasculitic lesions and premature atherosclerosis. The majority of the vasculitic lesions are short and ostial, involving the left main stem, left anterior descending and right coronary arteries [65,66]. In most centres, coronary artery bypass grafting $(C A B G)$ remains the preferred option in those who have symptomatic disease despite medical therapy (Figure 3C). Alternative intervention options include angioplasty (PCI) with or without stent insertion and coronary endarterectomy [66,67]. Rates of restenosis are higher following PCI when compared to CABG at follow-up of 100 months (63\% vs. 25\%) [67].

\subsection{Visceral Arteries}

Renal artery involvement in Takayasu arteritis can lead to refractory hypertension and renal ischaemia, which if overlooked can result in deterioration in renal function and loss of a kidney. The arterial lesions are commonly short and ostial. Longer more irregular lesions are occasionally observed, particularly if there is involvement of the adjacent aorta. Open surgical revascularisation with aorto-renal bypass is effective; however, the majority of patients will opt for an endovascular approach which is less invasive and has good long-term results [68]. Angioplasty alone is most common, with stent insertion carried out if there are complications or disease recurrence $[49,50,69]$.

Significant, symptomatic involvement of the visceral superior mesenteric artery or coeliac trunk is relatively rare. Persistent symptoms of mesenteric ischaemia merits intervention with angioplasty \pm stenting [51]. However, the results of intervention are mixed and re-stenosis rates are higher than those reported for renal artery angioplasty [50].

\section{Discussion}

Decisions concerning surgical intervention in Takayasu arteritis require multi-disciplinary input [7]. Earlier diagnosis and more aggressive immunosuppressive treatment, including access to biologics, is reducing the need for surgery. Furthermore, surgical outcomes are markedly improved when disease is inactive or disease activity is suppressed $[7,40]$. This often requires continuation of immunosuppressive drugs throughout the period surrounding the surgical procedure and this can be achieved safely. Ultimately, the decision between open surgery and endovascular approaches may rest with local expertise, the operator and the patient. The remarkable advances in vascular surgery will likely increase the options available to patients, particularly those with irreversible fixed, fibrotic stenotic lesions, and improve outcomes. Significant complications during or following surgical intervention in Takayasu arteritis are rare and are in part related to the type and site of intervention. Adverse events include bleeding, thrombosis, arterial dissection, stroke and restenosis. Surgical outcomes are good; particularly in those with inactive disease at the time of surgery. Planning patient follow-up following surgery is essential and should include regular non-invasive imaging. Communication between the intervention team and the medical team also involved in the care of the patient is required to facilitate comprehensive and safe long-term management.

Author Contributions: Both authors were involved in the draft preparation, writing and editing of this review article. All authors have read and agreed to the published version of the manuscript.

Funding: The authors wish to acknowledge support from the Imperial College, National Institute for Health Research, Biomedical Research Centre scheme.

Conflicts of Interest: The authors declare no conflict of interest.

\section{References}

1. Jennette, J.C.; Falk, R.J.; Bacon, P.A.; Basu, N.; Cid, M.C.; Ferrario, F.; Flores-Suarez, L.F.; Gross, W.L.; Guillevin, L.; Hagen, E.C.; et al. 2012 revised International Chapel Hill Consensus Conference Nomenclature of Vasculitides. Arthritis Rheum 2013, 65, 1-11. [CrossRef] [PubMed]

2. Mathew, A.J.; Goel, R.; Kumar, S.; Danda, D. Childhood-onset Takayasu arteritis: An update. Int. J. Rheumatol. Dis. 2016, 19, 116-126. [CrossRef] [PubMed] 
3. Mason, J.C. Takayasu arteritis-Advances in diagnosis and management. Nat. Rev. Rheumatol. 2010, 6, 406-415. [CrossRef] [PubMed]

4. Tombetti, E.; Mason, J.C. Takayasu arteritis: Advanced understanding is leading to new horizons. Rheumatology 2019, 58, 206-219. [CrossRef] [PubMed]

5. He, Y.; Lv, N.; Dang, A.; Cheng, N. Pulmonary Artery Involvement in Patients with Takayasu Arteritis. J. Rheumatol. 2020, 47, 264-272. [CrossRef]

6. Misra, D.P.; Wakhlu, A.; Agarwal, V.; Danda, D. Recent advances in the management of Takayasu arteritis. Int. J. Rheumatol. Dis. 2019, 22, 60-68. [CrossRef]

7. Perera, A.H.; Youngstein, T.; Gibbs, R.G.; Jackson, J.E.; Wolfe, J.H.; Mason, J.C. Optimizing the outcome of vascular intervention for Takayasu arteritis. Br. J. Surg. 2014, 101, 43-50. [CrossRef]

8. Tombetti, E.; Mason, J.C. Application of imaging techniques for Takayasu arteritis. La Presse Med. 2017, 46, e215-e223. [CrossRef]

9. Dejaco, C.; Ramiro, S.; Duftner, C.; Besson, F.L.; Bley, T.A.; Blockmans, D.; Brouwer, E.; Cimmino, M.A.; Clark, E.; Dasgupta, B.; et al. EULAR recommendations for the use of imaging in large vessel vasculitis in clinical practice. Ann. Rheum. Dis. 2018, 77, 636-643. [CrossRef]

10. Andrews, J.; Al-Nahhas, A.; Pennell, D.J.; Hossain, M.S.; Davies, K.A.; Haskard, D.O.; Mason, J.C. Non-invasive imaging in the diagnosis and management of Takayasu's arteritis. Ann. Rheum. Dis. 2004, 63, 995-1000. [CrossRef]

11. Quinn, K.A.; Ahlman, M.A.; Malayeri, A.A.; Marko, J.; Civelek, A.C.; Rosenblum, J.S.; Bagheri, A.A.; Merkel, P.A.; Novakovich, E.; Grayson, P.C. Comparison of magnetic resonance angiography and (18)F-fluorodeoxyglucose positron emission tomography in large-vessel vasculitis. Ann. Rheum. Dis. 2018, 77, 1165-1171. [PubMed]

12. Tombetti, E.; Godi, C.; Ambrosi, A.; Doyle, F.; Jacobs, A.; Kiprianos, A.P.; Youngstein, T.; Bechman, K.; Manfredi, A.A.; Ariff, B.; et al. Novel Angiographic Scores for evaluation of Large Vessel Vasculitis. Sci. Rep. 2018, 8, 15979. [CrossRef] [PubMed]

13. Sharma, S.; Rajani, M.; Talwar, K.K. Angiographic morphology in nonspecific aortoarteritis (Takayasu's arteritis): A study of 126 patients from north India. Cardiovasc. Interv. Radiol. 1992, 15, 160-165. [CrossRef]

14. Gornik, H.L.; Creager, M.A. Aortitis. Circulation 2008, 117, 3039-3051. [CrossRef] [PubMed]

15. Nazareth, R.; Mason, J.C. Takayasu arteritis: Severe consequences of delayed diagnosis. QJM 2011, 104, 797-800. [CrossRef] [PubMed]

16. Pryshchep, O.; Ma-Krupa, W.; Younge, B.R.; Goronzy, J.J.; Weyand, C.M. Vessel-specific Toll-like receptor profiles in human medium and large arteries. Circulation 2008, 118, 1276-1284. [CrossRef]

17. Terao, C. Revisited HLA and non-HLA genetics of Takayasu arteritis-where are we? J. Hum. Genet. 2016, 61, 27-32. [CrossRef]

18. Clement, M.; Galy, A.; Bruneval, P.; Morvan, M.; Hyafil, F.; Benali, K.; Pasi, N.; Deschamps, L.; Pellenc, Q.; Papo, T.; et al. Tertiary Lymphoid Organs in Takayasu Arteritis. Front. Immunol. 2016, 7, 158. [CrossRef]

19. Hata, A.; Noda, M.; Moriwaki, R.; Numano, F. Angiographic findings of Takayasu arteritis: New classification. Int. J. Cardiol. 1996, 54, S155-S163. [CrossRef]

20. Nasu, T. Takayasu's truncoarteritis. Pulseless disease or aortitis syndrome. Acta. Pathol. Jpn. 1982, 32, 117-131.

21. Moriwaki, R.; Noda, M.; Yajima, M.; Sharma, B.K.; Numano, F. Clinical manifestations of Takayasu arteritis in India and Japan-New classification of angiographic findings. Angiology 1997, 48, 369-379. [CrossRef] [PubMed]

22. Sato, E.I.; Hatta, F.S.; Levy-Neto, M.; Fernandes, S. Demographic, clinical, and angiographic data of patients with Takayasu arteritis in Brazil. Int. J. Cardiol. 1998, 66 (Suppl. 1), S67-S70. [CrossRef]

23. Goel, R.; Gribbons, K.B.; Carette, S.; Cuthbertson, D.; Hoffman, G.S.; Joseph, G.; Khalidi, N.A.; Koening, C.L.; Kumar, S.; Langford, C.; et al. Derivation of an angiographically based classification system in Takayasu's arteritis: An observational study from India and North. America. Rheumatology 2020, 59, 1118-1127. [CrossRef] [PubMed]

24. Lee, G.Y.; Jang, S.Y.; Ko, S.M.; Kim, E.K.; Lee, S.H.; Han, H.; Choi, S.H.; Kim, Y.W.; Choe, Y.H.; Kim, D.K. Cardiovascular manifestations of Takayasu arteritis and their relationship to the disease activity: Analysis of 204 Korean patients at a single center. Int. J. Cardiol. 2012, 159, 14-20. [CrossRef] 
25. Porter, A.; Youngstein, T.; Tombetti, E.; Mason, J.C. Biologic therapy in supra-aortic Takayasu arteritis can improve symptoms of cerebral ischaemia without surgical intervention. Rheumatology 2020, 59, iii28-iii32. [CrossRef]

26. Mason, J.C. Surgical intervention and its role in Takayasu arteritis. Best Pract. Res. Clin. Rheumatol. 2018, 32, 112-124. [CrossRef]

27. Maksimowicz-McKinnon, K.; Clark, T.M.; Hoffman, G.S. Limitations of therapy and a guarded prognosis in an American cohort of Takayasu arteritis patients. Arthritis Rheum. 2007, 56, 1000-1009. [CrossRef]

28. Valsakumar, A.K.; Valappil, U.C.; Jorapur, V.; Garg, N.; Nityanand, S.; Sinha, N. Role of immunosuppressive therapy on clinical, immunological, and angiographic outcome in active Takayasu's arteritis. J. Rheumatol. 2003, 30, 1793-1798.

29. Shelhamer, J.H.; Volkman, D.J.; Parrillo, J.E.; Lawley, T.J.; Johnston, M.R.; Fauci, A.S. Takayasu's arteritis and its therapy. Ann. Intern. Med. 1985, 103, 121-126. [CrossRef]

30. de Souza, A.W.; da Silva, M.D.; Machado, L.S.; Oliveira, A.C.; Pinheiro, F.A.; Sato, E.I. Short-term effect of leflunomide in patients with Takayasu arteritis: An observational study. Scand. J. Rheumatol. 2012, 41, 227-230. [CrossRef]

31. Goel, R.; Danda, D.; Mathew, J.; Edwin, N. Mycophenolate mofetil in Takayasu's arteritis. Clin. Rheumatol. 2010, 29, 329-332. [CrossRef] [PubMed]

32. Bechman, K.; Gopalan, D.; Nihoyannopoulos, P.; Mason, J.C. A cohort study reveals myocarditis to be a rare and life-threatening presentation of large vessel vasculitis. Semin. Arthritis Rheum. 2017, 47, 241-246. [CrossRef] [PubMed]

33. NHS-England. Clinical Commissioning Policy: Tocilizumab for Takayasu Arteritis (Adults); NHS England: 16056/P. England, 2016.

34. Ishikawa, K.; Maetani, S. Long-term outcome for 120 Japanese patients with Takayasu's disease. Clinical and statistical analyses of related prognostic factors. Circulation 1994, 90, 1855-1860. [CrossRef] [PubMed]

35. Miyata, T.; Sato, O.; Koyama, H.; Shigematsu, H.; Tada, Y. Long-term survival after surgical treatment of patients with Takayasu's arteritis. Circulation 2003, 108, 1474-1480. [CrossRef] [PubMed]

36. Labarca, C.; Makol, A.; Crowson, C.S.; Kermani, T.A.; Matteson, E.L.; Warrington, K.J. Retrospective Comparison of Open versus Endovascular Procedures for Takayasu Arteritis. J. Rheumatol. 2016, 43, 427-432. [CrossRef]

37. Yang, L.; Zhang, H.; Jiang, X.; Zou, Y.; Qin, F.; Song, L.; Guan, T.; Wu, H.; Xu, L.; Liu, Y.; et al. Clinical manifestations and longterm outcome for patients with Takayasu arteritis in China. J. Rheumatol. 2014, 41, 2439-2446. [CrossRef]

38. Fields, C.E.; Bower, T.C.; Cooper, L.T.; Hoskin, T.; Noel, A.A.; Panneton, J.M.; Sullivan, T.M.; Gloviczki, P.; Cherry, K.J., Jr. Takayasu's arteritis: Operative results and influence of disease activity. J. Vasc. Surg. 2006, 43, 64-71. [CrossRef]

39. Ohigashi, H.; Haraguchi, G.; Konishi, M.; Tezuka, D.; Kamiishi, T.; Ishihara, T.; Isobe, M. Improved prognosis of Takayasu arteritis over the past decade-Comprehensive analysis of 106 patients. Circ. J. 2012, 76, 1004-1011. [CrossRef]

40. Saadoun, D.; Lambert, M.; Mirault, T.; Resche-Rigon, M.; Koskas, F.; Cluzel, P.; Mignot, C.; Schoindre, Y.; Chiche, L.; Hatron, P.Y.; et al. Retrospective analysis of surgery versus endovascular intervention in Takayasu arteritis: A multicenter experience. Circulation 2012, 125, 813-819. [CrossRef]

41. Misra, R.; Danda, D.; Rajappa, S.M.; Ghosh, A.; Gupta, R.; Mahendranath, K.M.; Jeyaseelan, L.; Lawrence, A.; Bacon, P.A.; Indian Rheumatology Vasculitis Groups. Development and initial validation of the Indian Takayasu Clinical Activity Score (ITAS2010). Rheumatology 2013, 52, 1795-1801. [CrossRef]

42. Grayson, P.C.; Alehashemi, S.; Bagheri, A.A.; Civelek, A.C.; Cupps, T.R.; Kaplan, M.J.; Malayeri, A.A.; Merkel, P.A.; Novakovich, E.; Bluemke, D.A.; et al. (18) F-Fluorodeoxyglucose-Positron Emission Tomography As an Imaging Biomarker in a Prospective, Longitudinal Cohort of Patients With Large Vessel Vasculitis. Arthritis Rheumatol. 2018, 70, 439-449. [CrossRef] [PubMed]

43. Lee, B.B.; Laredo, J.; Neville, R.; Villavicencio, J.L. Endovascular management of takayasu arteritis: Is it a durable option? Vascular 2009, 17, 138-146. [CrossRef] [PubMed]

44. Jung, J.H.; Lee, Y.H.; Song, G.G.; Jeong, H.S.; Kim, J.H.; Choi, S.J. Endovascular Versus Open Surgical Intervention in Patients with Takayasu's Arteritis: A Meta-analysis. Eur. J. Vasc. Endovasc. Surg. 2018, 55, 888-899. [CrossRef] [PubMed] 
45. Matsuura, K.; Ogino, H.; Kobayashi, J.; Ishibashi-Ueda, H.; Matsuda, H.; Minatoya, K.; Sasaki, H.; Bando, K.; Niwaya, K.; Tagusari, O.; et al. Surgical treatment of aortic regurgitation due to Takayasu arteritis: Long-term morbidity and mortality. Circulation 2005, 112, 3707-3712. [CrossRef] [PubMed]

46. Perera, A.H.; Mason, J.C.; Wolfe, J.H. Takayasu arteritis: Criteria for surgical intervention should not be ignored. Int. J. Vasc. Med. 2013, 2013, 618910. [CrossRef]

47. Dogan, A.; Sever, K.; Ozdemir, E.; Mansuroglu, D.; Kurtoglu, N. Endovascular stenting of mid-aortic syndrome due to Takayasu arteritis. Acta Chir. Belg. 2018, 118, 264-268. [CrossRef]

48. Ghazi, P.; Haji-Zeinali, A.M.; Shafiee, N.; Qureshi, S.A. Endovascular abdominal aortic stenosis treatment with the OptiMed self-expandable nitinol stent. Catheter. Cardiovasc. Interv. 2009, 74, 634-641. [CrossRef]

49. Park, H.S.; Do, Y.S.; Park, K.B.; Kim, D.K.; Choo, S.W.; Shin, S.W.; Cho, S.K.; Hyun, D.; Choo, I.W. Long term results of endovascular treatment in renal arterial stenosis from Takayasu arteritis: Angioplasty versus stent placement. Eur. J. Radiol. 2013, 82, 1913-1918. [CrossRef]

50. Sharma, S.; Gupta, A. Visceral Artery Interventions in Takayasu's Arteritis. Semin. Interv. Radiol. 2009, 26, 233-244. [CrossRef]

51. Jeong, H.S.; Jung, J.H.; Song, G.G.; Choi, S.J.; Hong, S.J. Endovascular balloon angioplasty versus stenting in patients with Takayasu arteritis: A meta-analysis. Medicine 2017, 96, e7558. [CrossRef]

52. Peng, M.; Ji, W.; Jiang, X.; Dong, H.; Zou, Y.; Song, L.; Zhang, H.; Zhang, W.; Yang, Y.; Gao, R. Selective stent placement versus balloon angioplasty for renovascular hypertension caused by Takayasu arteritis: Two-year results. Int. J. Cardiol. 2016, 205, 117-123. [CrossRef] [PubMed]

53. Kim, Y.W.; Kim, D.I.; Park, Y.J.; Yang, S.S.; Lee, G.Y.; Kim, D.K.; Kim, K.; Sung, K. Surgical bypass vs endovascular treatment for patients with supra-aortic arterial occlusive disease due to Takayasu arteritis. J. Vasc. Surg. 2012, 55, 693-700. [CrossRef] [PubMed]

54. Han, H.S.; Yoon, K.W.; Heo, S.H.; Park, Y.J.; Kim, Y.W.; Kim, D.I. Aorto-carotid bypass in patients with Takayasu arteritis. Ann. Surg. Treat. Res. 2017, 93, 143-151. [CrossRef] [PubMed]

55. Tada, Y.; Kamiya, K.; Shindo, S.; Miyata, T.; Koyama, H.; Sato, O.; Ariizumi, K. Carotid artery reconstruction for Takayasu's arteritis the necessity of all-autogenous-vein graft policy and development of a new operation. Int. Angiol. 2000, 19, 242-249.

56. Chen, B.; Yu, H.X.; Zhang, J.; Li, X.X.; Wu, X.G.; Yang, S.J.; Qi, Y.X.; Yan, C.; Wang, Z.G. Endovascular revascularization for carotid artery occlusion in patients with Takayasu arteritis. Eur. J. Vasc. Endovasc. Surg. 2015, 49, 498-505. [CrossRef]

57. Tyagi, S.; Verma, P.K.; Gambhir, D.S.; Kaul, U.A.; Saha, R.; Arora, R. Early and long-term results of subclavian angioplasty in aortoarteritis (Takayasu disease): Comparison with atherosclerosis. Cardiovasc. Interv. Radiol. 1998, 21, 219-224. [CrossRef]

58. Ogino, H.; Matsuda, H.; Minatoya, K.; Sasaki, H.; Tanaka, H.; Matsumura, Y.; Ishibashi-Ueda, H.; Kobayashi, J.; Yagihara, T.; Kitamura, S. Overview of late outcome of medical and surgical treatment for Takayasu arteritis. Circulation 2008, 118, 2738-2747. [CrossRef]

59. Yang, K.Q.; Meng, X.; Zhang, Y.; Fan, P.; Wang, L.P.; Zhang, H.M.; Wu, H.Y.; Jiang, X.J.; Cai, J.; Zhou, X.L.; et al. Aortic Aneurysm in Takayasu Arteritis. Am. J. Med. Sci. 2017, 354, 539-547. [CrossRef]

60. Angle, J.F.; Nida, B.A.; Matsumoto, A.H. Endovascular treatment of large vessel arteritis. Tech. Vasc. Interv. Radiol. 2014, 17, 252-257. [CrossRef]

61. Kieffer, E.; Chiche, L.; Bertal, A.; Koskas, F.; Bahnini, A.; Bla Try, O.; Cacoub, P.; Piette, J.C.; Thomas, D. Descending thoracic and thoracoabdominal aortic aneurysm in patients with Takayasu's disease. Ann. Vasc. Surg. 2004, 18, 505-513. [CrossRef]

62. Taketani, T.; Miyata, T.; Morota, T.; Takamoto, S. Surgical treatment of atypical aortic coarctation complicating Takayasu's arteritis-experience with 33 cases over 44 years. J. Vasc. Surg. 2005, 41, 597-601. [CrossRef] [PubMed]

63. Min, P.K.; Park, S.; Jung, J.H.; Ko, Y.G.; Choi, D.; Jang, Y.; Shim, W.H. Endovascular therapy combined with immunosuppressive treatment for occlusive arterial disease in patients with Takayasu's arteritis. J. Endovasc. Ther. 2005, 12, 28-34. [CrossRef] [PubMed]

64. Yang, K.Q.; Yang, Y.K.; Meng, X.; Zhang, Y.; Zhang, H.M.; Wu, H.Y.; Liu, Y.X.; Jiang, X.J.; Cai, J.; Zhou, X.L.; et al. Aortic Dissection in Takayasu Arteritis. Am. J. Med. Sci. 2017, 353, 342-352. [CrossRef] [PubMed] 
65. Kang, E.J.; Kim, S.M.; Choe, Y.H.; Lee, G.Y.; Lee, K.N.; Kim, D.K. Takayasu arteritis: Assessment of coronary arterial abnormalities with 128-section dual-source CT angiography of the coronary arteries and aorta. Radiology 2014, 270, 74-81. [CrossRef]

66. Endo, M.; Tomizawa, Y.; Nishida, H.; Aomi, S.; Nakazawa, M.; Tsurumi, Y.; Kawana, M.; Kasanuki, H. Angiographic findings and surgical treatments of coronary artery involvement in Takayasu arteritis. J. Thorac. Cardiovasc. Surg. 2003, 125, 570-577. [CrossRef]

67. Yang, Y.; Tian, T.; Yang, Y.; Zhang, K.; Meng, X.; Fan, P.; Feng, L.; Mu, C.; Gao, L.; Zhou, X. Outcomes of percutaneous coronary intervention and coronary artery bypass grafting in patients with Takayasu arteritis. Int. J. Cardiol. 2017, 241, 64-69. [CrossRef]

68. Weaver, F.A.; Kumar, S.R.; Yellin, A.E.; Anderson, S.; Hood, D.B.; Rowe, V.L.; Kitridou, R.C.; Kohl, R.D.; Alexander, J. Renal revascularization in Takayasu arteritis-induced renal artery stenosis. J. Vasc. Surg. 2004, 39, 749-757. [CrossRef]

69. Kinjo, H.; Kafa, A. The results of treatment in renal artery stenosis due to Takayasu disease: Comparison between surgery, angioplasty, and stenting. A monocentrique retrospective study. G. Chir. 2015, 36, 161-167. [CrossRef]

(C) 2020 by the authors. Licensee MDPI, Basel, Switzerland. This article is an open access article distributed under the terms and conditions of the Creative Commons Attribution (CC BY) license (http://creativecommons.org/licenses/by/4.0/). 